\title{
Exploring the factors that contribute towards better student-mentor relationship in work- based learning (WBL) practice
}

\author{
${ }^{1}$ Abdool Qaiyum Mohabuth*, 2Syed Munir Ahmad \\ ${ }^{1}$ University of Mauritius, Reduit, Mauritius \\ 2University of Peshawar, Peshawar, Pakistan \\ *a.mohabuth@uom.ac.mu
}

\begin{abstract}
Mentors are called upon to counsel, guide, coach and advise mentees. Mentoring creates a relationship with the purpose of facilitating learners to achieve their learning goals. It allows individuals to look objectively at their performance and future development. Mentoring takes a formal setting in WBL practice which involves an experience for learning and a change in which mentor and mentee utilize a range of core components including honesty, trust and respectful listening to transfer knowledge and skills. Students on WBL practice view mentors as the right professionals with advanced work experience and knowledge from whom they may seek assistance for their professional and personal development. While many students undertaking WBL practice have experienced positive mentoring, there are some that complain about the lack of attention and care provided by their mentors. Most studies investigated the antecedents, outcomes, and benefits of programs with little attention given to identifying and illustrating what is required to ensure the quality of the mentoring process and the effectiveness of the mentoring relationship. This study sought to identify the factors that contribute towards positive mentoring for enhancing the student-mentor relationship. A survey questionnaire was designed for exploring the factors that lead to positive mentoring in WBL practice. The questionnaire was administered to students of the University of Mauritius who undertook WBL practice at the respective placement settings. Mentors providing the necessary coaching at these practice settings were also requested to complete a questionnaire. The findings reveal a list of the main factors which can lead to successful mentoring and enhance the student-mentor relationship. The element of 'trust' was found to be the most influential factor in the relationship, followed by 'empathy' and 'openness'. These factors are seen to enhance interactive capability of mentees which contribute much towards improved acquisition of knowledge and skills in the practice.
\end{abstract}

Keywords: Mentoring, Coach, Guide, Placement settings, Trust

\section{Introduction}

Mentoring in WBL involves discussing, demonstrating and practicing tasks that centre on developing knowledge, skills and understanding of mentees. Mentors and mentees are called upon to work, share and care for achieving stipulated goals. Proper mentoring helps mentees to have greater potential for enhanced understanding and the learning is unlocked if there is good guidance. The quality of the mentor-mentee relationship is important as learning takes place in a social context. Stewart and Knowles (2003) highlighted the value and importance of learning through work and the significant role that can be played in the process by mentoring. Workplace mentoring linked to WBL requires a partnership and commitment that involves time, energy and resources. Workplace mentoring requires planning, training, monitoring and assessment to ensure that the students being mentored achieve success. For ensuring learning effectiveness, the mentor must have relevant experience, which is valuable to the mentee and the mentee must take responsibility for his/her own learning. Mentees are expected to reflect on their learning and improve their learning in the practice. Mentors are supposed to provide them with the necessary support for mentees to achieve their learning objectives. They act as the facilitators for the mentees, but the responsibility of learning rests on mentees' own effort and contribution to the work place. 


\section{Literature Review}

The term mentoring was introduced in the late 1960's in the USA. Clutterbuck (1991, p. 2) cited Ralf Stodgill, who in 1960's viewed the mentor as an ambiguous authority figure. There was at the time much confusion as regards to the role of a mentor and about how it differed from that of a teacher. Wider debates on mentoring were held defining its role and importance in education and in organizations. There were various new discussions of mentoring in the 1990's as its use was propagated on higher scale. Crucially, Clutterbuck (1991, p. 5) cites Agnes Missirian who put forward that there is some recognitions that successful mentoring relationships lead to friendships. Furthermore, Miller (2002) described mentoring as a personal relationship between the mentor and the mentee. Although, mentoring differs from teaching, it uses a teaching approach as and when appropriate. Hirst (1971, p. 165) described teaching as an activity involving 'questioning'. Hirst (1971, p. 170) viewed objectives and end achievements of learning through mentoring as being new 'states of the person'. May et al (1982) defined mentoring as "an intense relationship" between a novice and a wise knowledgeable person, whereas Andrews \& Wallis (1999) defined it as a "long-term relationship" that promotes the novice's well-being. Other descriptions include "a special way to transfer knowledge" (Byrne \& Keefe, 2002), "a learning relationship" (Dingman, 2002), a "critical companionship" (Titchen, 2003) and "a process in which two or more people create a connection and safe environment that allow healing truth and wisdom to be discovered" (Swanson, 2000: p. 31).

Mentoring involves coaching which Kalinauckas \& King (1994) defined as a process which aims to bring out the best in people. Their view is that coaching involves a discussion to gain commitment to take action leading to a result or 'goal'. Kalinauckas \& King (1994, p. 10) defined mentoring as 'providing individuals with the opportunity, through regular discussion, to look objectively at their performance and future development.' Cull (2006) argued that for effective mentoring relationships to be developed between mentors and mentees there is a need to adopt both a "pulling" and "pushing" style. This is featured as a sanctuary and a safe place where the mentee feels able to share their ideas, interests and goals. The mentor on their side is able to offer support by listening, asking the right questions, helping the mentee arrive at their own answers to their problems. In doing so, the mentee is able to stimulate creative ideas, cope with challenges, develop knowledge, apply mental models, use tools and techniques and acquire wisdom. Donovan (1990) stated that a mentor is a wise counselor and a trusted teacher, personified by the mythological character. In addition, Devojine \& Harris (2001) suggested that mentors can engage in to help deepen and develop effective mentoring relationships such as creating a safe environment, listening without judgment, focusing on listening, agreeing on objectives rather than on approaches and appreciating differences. They similarly reflect the range of skills and abilities that Klasen \& Clutterbuck (2002) argue mentors need to deploy to be effective, such as: self and behavioral awareness; building and maintaining rapport and relationship management through trust; focus; empathy; congruence as well as empowerment. Kram \& Hall (1989) further added that mentoring has been recognized increasingly as a powerful human resource development intervention that can assist both employees and trainees in career advancement, serves as a form of on-the-job training, and helps create learning organizations. Good mentors are often viewed as being friendly, approachable, having a good degree of understandability and patience. For mentors to be most effective they need to be perceived as honest, respectful, dedicated, compassionate, having integrity and be willing and skilled to provide honest feedback (McDowall-Long, 2004).

On the other hand, good mentees are considered to be those who would listen, act on advice, show a willingness, desire and commitment to learn and grow, and be opened to feedback and criticism with willingness to change. Audet (2009) identified four important factors that influence mentee satisfaction, namely (1) meeting efficiency (2) mutual trust (3) mentee belief that their mentor truly understands their situation and (4) mutual respect. However, due to socio cultural and other factors, functional and effective mentor-mentee relationship may be difficult to achieve. Wanberg et al. (2007) argued that the mentoring relationships can prove to be difficult due to the fact that at the outset mentors and mentees typically do not know each other, and their respective dyadic relationships have to be developed from scratch in the context of the limited duration of programs. Furthermore, some mentors may disappoint their mentees, either in the way they mentor, or by not meeting some or even most of their mentee's development needs. Ragins et al. (2000) defined this shortcoming as marginal mentoring. Eby et al. (2000) used the term negative mentoring to classify specific incidents that occur between mentors and mentees, mentors' characteristic manner of 
interacting with mentees, or mentors' characteristics that limit their ability to effectively provide guidance to mentees.

\section{Methodology}

Two sets of questionnaires were developed. One was administered to students to gather relevant information on the kind of mentee relationship they had with their mentors. The second set of questionnaire was for mentors who had coached students during their WBL practice. Both questionnaires contained three separate sections that included eight Likert scale questions in section A to rate the importance of the factors identified in the student-mentor relationship (rating scale 1-5: 1: not important (NI), 2: a little important (LI), 3: Neutral (N), 4: Important (I) - 5: Very Important (V)). Section B included twelve Likert scale questions and sought information on the perceptions of students and mentors about the kind of mentorship received and provided. Section C sought self-information about respondents as regards to the Faculty, year of study, program, placement settings, experience in mentoring etc. In each section, open-ended questions were provided for enabling respondents to share their experiences and insights. The mentor's questionnaire was administered to 50 mentors based on probability random sampling technique. The mentors were sorted on a list in alphabetical order and the selection of the 50 mentors was made by using an integer random generator. On the other hand, the student's questionnaire was administered to 100 undergraduate students who were distributed across four Faculties. To obtain a good representation of the students, the sample was stratified over the Faculties with selection of 25 students from each Faculty of (1) Faculty of Law \& Management (FLM), (2) Faculty of Science (FOS) and (3) Faculty of Social Studies \& Humanities (FSSH) and (4) Faculty of Engineering (FOE). Same selection process was used, similar to the mentor's questionnaire i.e. random sampling technique followed by the application of the integer random generator.

\section{Results and Discussion}

The quantitative data were analyzed using SPSS version 21. Table 1 to 8 shows the result generated from the student's questionnaire as regards to the level of importance of the factors identified in the student-mentor relationship as experienced by male and female students.

Table 1: The level of importance of Openness

\begin{tabular}{llllll}
\hline & & LI & N & I & V \\
\hline Gender & Male & & $1.2 \%$ & $7.1 \%$ & $15.5 \%$ \\
& Female & $1.2 \%$ & $4.8 \%$ & $26.2 \%$ & $44.0 \%$ \\
Total & & $1.2 \%$ & $6.0 \%$ & $33.3 \%$ & $59.5 \%$ \\
\hline
\end{tabular}

Table 3: The level of importance of Trust

\begin{tabular}{lllll}
\hline & & $\mathbf{N}$ & $\mathbf{I}$ & $\mathbf{V}$ \\
\hline Gender & Male & $1.2 \%$ & $3.6 \%$ & $19.3 \%$ \\
& Female & $1.2 \%$ & $22.9 \%$ & $51.8 \%$ \\
Total & & $2.4 \%$ & $26.5 \%$ & $71.1 \%$ \\
\hline
\end{tabular}

Table 5: The level of importance of Care

\begin{tabular}{llllll}
\hline & & LI & N & I & V \\
\hline Gender & Male & & $2.4 \%$ & $6.0 \%$ & $15.5 \%$ \\
& Female & $1.2 \%$ & & $34.5 \%$ & $40.5 \%$ \\
Total & & $1.2 \%$ & $2.4 \%$ & $40.5 \%$ & $56.0 \%$ \\
\hline
\end{tabular}

Table 7: The level of importance of Respect

\begin{tabular}{llllll}
\hline & & NI & N & I & V \\
\hline Gender & Male & $1.2 \%$ & $3.6 \%$ & $4.8 \%$ & $14.5 \%$ \\
& Female & & $4.8 \%$ & $25.3 \%$ & $45.8 \%$ \\
Total & & $1.2 \%$ & $8.4 \%$ & $30.1 \%$ & $60.2 \%$ \\
\hline
\end{tabular}

Table 2: The level of importance of Honesty

\begin{tabular}{llllll}
\hline & & LI & N & I & V \\
\hline Gender & Male & & $3.6 \%$ & $8.3 \%$ & $11.9 \%$ \\
& Female & $2.4 \%$ & $1.2 \%$ & $34.5 \%$ & $38.1 \%$ \\
Total & & $2.4 \%$ & $4.8 \%$ & $42.9 \%$ & $50.0 \%$ \\
\hline
\end{tabular}

Table 4: The level of importance of Empathy

\begin{tabular}{llllll}
\hline \multicolumn{2}{c}{} & LI & N & I & V \\
\hline Gender & Male & & & $4.8 \%$ & $19.0 \%$ \\
& Female & $2.4 \%$ & $4.8 \%$ & $21.4 \%$ & $47.6 \%$ \\
Total & & $2.4 \%$ & $4.8 \%$ & $26.2 \%$ & $66.7 \%$
\end{tabular}

Table 6: Level of importance of Understandability

\begin{tabular}{lllllll}
\hline & & NI & LI & N & I & V \\
\hline Gender & Male & $1.2 \%$ & & & $8.3 \%$ & $14.3 \%$ \\
& Female & & $3.6 \%$ & $3.6 \%$ & $39.3 \%$ & $29.8 \%$ \\
Total & & $1.2 \%$ & $3.6 \%$ & $3.6 \%$ & $47.6 \%$ & $44.0 \%$ \\
\hline
\end{tabular}

Table 8: The level of importance of Loyalty

\begin{tabular}{llllll}
\hline & & LI & N & I & V \\
\hline Gender & Male & & $1.2 \%$ & $9.5 \%$ & $13.1 \%$ \\
& Female & $1.2 \%$ & $2.4 \%$ & $35.7 \%$ & $36.9 \%$ \\
Total & & $1.2 \%$ & $3.6 \%$ & $45.2 \%$ & $50.0 \%$ \\
\hline
\end{tabular}




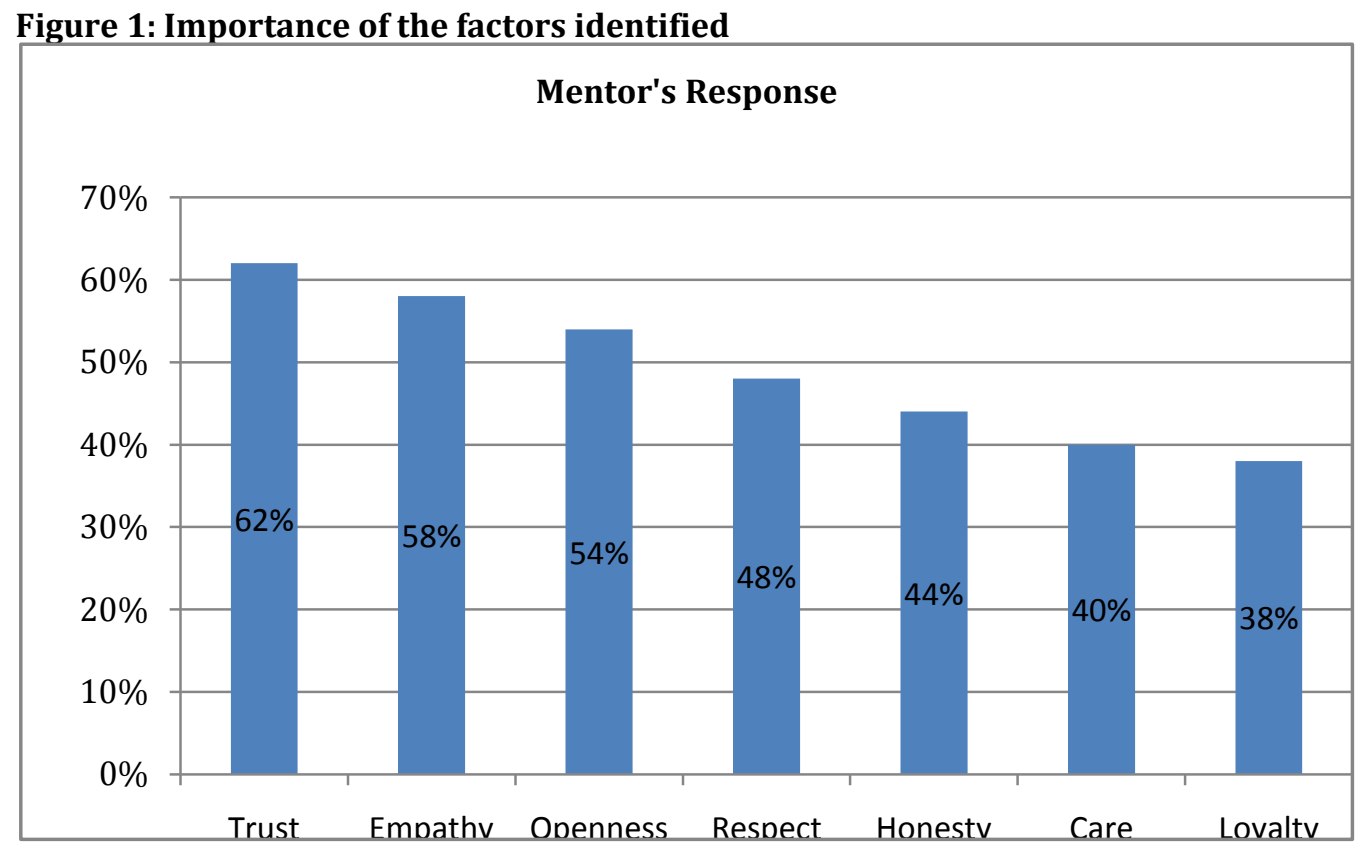

Figure 1 shows the importance of the factors as perceived by the mentors. It is to be noted that in both cases the percentage of female students and female mentors classifying these factors as being very important are more pronounced than male students and male mentors. The element of 'trust' comes out as the most important factor in mentor-mentee relationship since $71 \%$ students classified it as being very important. The response rate is relatively similar as regards to mentors with $62 \%$ of them classifying 'trust' in the first position. In fact Podsen \& Denmark (2000) confirmed that trust helps students in connecting with their mentors and strengthening the relationship. This is followed by 'empathy' which is rated as very important by $66.7 \%$ students and 58\% mentors. Once 'trust' is established between a mentor and a student, 'empathy' makes its way enabling the student to discuss matters freely with the mentor. Nermanick (2013) stated that a student looks for empathy from a mentor because a mentor has already been in the student's shoes before. When a mentor empathizes with a student, $\mathrm{s} / \mathrm{he}$ is connecting with a time when $\mathrm{s} / \mathrm{he}$ felt how the student feels now because s/he has had a similar experience in the past. Mentors often have the ability to truly empathies with students, which can strengthen the connection between them. $59.6 \%$ of the students identified 'openness' as being very important in the establishment of a good student-mentor relationship, while $52 \%$ of the mentors agreed about its importance. In fact, many studies have ranked 'openness' as the factor that comes just after empathy. Openness allows the sharing of ideas and knowledge; it improves connections and breaks barriers to facilitate the learning process. Sunderhaus (2012) rightly said that openness leads to tolerance, emotional flexibility and receptivity to new experiences and ideas. Without openness, transfer of knowledge is restricted and the learner's enthusiasm to progress further is found to be limited.

'Respect' was rated as the fourth important factor as it allows mentors and mentees to engage together. Straus et al. (2013) said that mentors and mentees need to respect each other's time, effort and qualifications. If the mentee does not respect the mentor's time or advice, the mentor may disengage. Respect enables the pair to share interest and values. The element of 'care' occupied fifth position for students, while with mentors it ranked on sixth position. Knowing self and others, patience, humility, hope of possible and courage are the major ingredients in caring. Mayeroff claimed that caring gives order, meaning, and stability to life and that change occurs in the 'carer' and the 'cared-for'. Watson (1999) stated that the 'caring moment' is similar to the 'mentoring moment,' where the carer and the cared-for share on a personal level, creating a mutual opportunity for learning from each other. $50 \%$ of the students classified loyalty and honesty as being very important. In fact, loyalty describes the feeling that students attached to their mentors. It is conceived as a means to an end, commonly referred to as retention. $44 \%$ mentors rated honesty as very important ranking 
it on fifth position on the mentor's side, with $40 \%$ for the element of 'care' before 'loyalty' as the last important factor. A student will stay and work with their mentors if the four elements (trust, empathy, respect, openness) are present. Retention will not be possible in the absence of these four elements which received the same order of importance for both mentors and students in the study. Honesty may appear simple, but it is hard to develop. It makes relationships valuable and durable. It allows real exchange of viewpoints and feedback. This cannot happen if the other factors mentioned are omitted. In addition, the distribution of the eight factors as regards to the four Faculties representation is illustrated in Table 9

Table 9: Distribution of the importance of identified factors with respect to Faculties

\begin{tabular}{|c|c|c|c|c|c|c|c|c|c|}
\hline \multirow{3}{*}{$\begin{array}{l}\text { You } \\
\text { from } \\
\text { FOE }\end{array}$} & \multicolumn{6}{|c|}{ The level of importance of } & \multirow[b]{2}{*}{ Care } & \multirow{2}{*}{\multicolumn{2}{|c|}{ Understandability Respec }} \\
\hline & $\begin{array}{l}\text { are student } \\
\text { which Faculty }\end{array}$ & Openness & Hone & Trus & Emp & Loyalty & & & \\
\hline & Mean & 4.50 & 4.40 & 4.65 & 4.65 & 4.55 & 4.65 & 4.45 & 4.45 \\
\hline & Std. Deviation & .827 & .821 & .489 & .745 & .605 & .489 & .759 & .759 \\
\hline \multirow[t]{2}{*}{ FLM } & Mean & 4.36 & 4.36 & 4.86 & 4.55 & 4.23 & 4.41 & 4.18 & 4.71 \\
\hline & Std. Deviation & 658 & .581 & .359 & .800 & .429 & .734 & .907 & .463 \\
\hline \multirow[t]{2}{*}{ FOS } & Mean & 4.63 & 4.21 & 4.74 & 4.50 & 4.53 & 4.63 & 4.42 & 4.05 \\
\hline & Std. Deviation & .597 & .855 & .562 & .618 & .612 & .597 & .769 & 1.129 \\
\hline \multirow{2}{*}{ FSSH } & Mean & 4.60 & 4.64 & 4.56 & 4.60 & 4.48 & 4.44 & 4.24 & 4.56 \\
\hline & Std. Deviation & .577 & .490 & .583 & .645 & .770 & .583 & .779 & .651 \\
\hline
\end{tabular}

Trust in relationships was found to have the highest positive mean in three out of the four Faculties. This denotes once again the importance of the factor 'Trust' in the student-mentor relationship. It is to be noted that there are no negative means and all the means value are higher than 4 which illustrates that these factors have been rated as important or very important across all the four Faculties. Investigation was also carried out to determine whether students receive proper mentorship from their mentors. The descriptive statistics of the 12 items on the Likert scale distributed over the four Faculties are illustrated in table 10. The means across the four Faculties are highly positive indicating that the mentors are well engaged in facilitating students' learning. They are found to be appreciated for their role mentorship role.

Table 10: Views of Mentorship role by Faculties

\begin{tabular}{lllll}
\hline Mentorship & Groups & Mean & SD & Median \\
\hline I can rely on my mentor for learning at & FLM & 3.79 & 0.787 & 4 \\
the practice setting & FOS & 4.05 & 0.621 & 4 \\
& FOE & 4.65 & 0.587 & 5 \\
My mentor provides to me the necessary & FSSH & 3.84 & 0.987 & 4 \\
instructions before embarking on new & FOS & 3.74 & 0.991 & 4 \\
task & FOE & 4.11 & 0.809 & 4 \\
& FSSH & 4.34 & 0.571 & 4 \\
My mentor is always willing to help & FLM & 3.63 & 0.997 & 4 \\
& FOS & 4.37 & 0.684 & 4 \\
& FOE & 4.45 & 0.999 & 5 \\
My mentor always encourages me & FSSH & 4.20 & 0.816 & 4 \\
& FLM & 3.95 & 0.970 & 4 \\
& FOS & 4.37 & 0.597 & 4 \\
& FOE & 3.95 & 1.050 & 4 \\
& FSSH & 3.92 & 1.067 & 4
\end{tabular}




\begin{tabular}{|c|c|c|c|c|}
\hline Mentorship & Groups & Mean & SD & Median \\
\hline \multirow{4}{*}{$\begin{array}{l}\text { My mentor asks me questions after } \\
\text { providing necessary instructions }\end{array}$} & FLM & 4.11 & 1.150 & 4 \\
\hline & FOS & 4.68 & 0.478 & 5 \\
\hline & FOE & 4.45 & 1.050 & 5 \\
\hline & FSSH & 4.24 & 0.663 & 4 \\
\hline \multirow{4}{*}{$\begin{array}{l}\text { My mentor provides to me feedback } \\
\text { about my performance }\end{array}$} & FLM & 4.42 & 0.769 & 5 \\
\hline & FOS & 4.32 & 0.478 & 4 \\
\hline & FOE & 4.35 & 0.988 & 5 \\
\hline & FSSH & 4.32 & 0.690 & 4 \\
\hline \multirow[t]{4}{*}{ My mentor monitors my training well } & FLM & 3.89 & 0.994 & 4 \\
\hline & FOS & 4.42 & 0.692 & 5 \\
\hline & FOE & 4.25 & 0.786 & 4 \\
\hline & FSSH & 4.28 & 0.843 & 4 \\
\hline \multirow[t]{4}{*}{ My mentor is supportive } & FLM & 3.79 & 0.713 & 4 \\
\hline & FOS & 4.00 & 0.745 & 4 \\
\hline & FOE & 4.05 & 1.050 & 4 \\
\hline & FSSH & 4.20 & 0.764 & 4 \\
\hline \multirow{4}{*}{ My mentor engages me in team working } & FLM & 3.84 & 0.898 & 4 \\
\hline & FOS & 4.42 & 0.692 & 5 \\
\hline & FOE & 4.10 & 0.607 & 5 \\
\hline & FSSH & 3.76 & 0.970 & 4 \\
\hline \multirow{4}{*}{$\begin{array}{l}\text { I have no problem discussing with my } \\
\text { mentor about things that I don't } \\
\text { understand }\end{array}$} & FLM & 3.79 & 0.787 & 4 \\
\hline & FOS & 4.21 & 0.787 & 4 \\
\hline & FOE & 4.40 & 0.821 & 5 \\
\hline & FSSH & 4.00 & 0.951 & 4 \\
\hline \multirow{4}{*}{$\begin{array}{l}\text { My mentor listens to my problems and } \\
\text { apprehensions }\end{array}$} & FLM & 3.63 & 1.300 & 4 \\
\hline & FOS & 4.11 & 0.809 & 4 \\
\hline & FOE & 4.30 & 0.733 & 4 \\
\hline & FSSH & 3.80 & 0.957 & 4 \\
\hline \multirow[t]{4}{*}{ My mentor always does the right things } & FLM & 3.58 & 1.305 & 4 \\
\hline & FOS & 4.21 & 0.918 & 5 \\
\hline & FOE & 4.15 & 0.745 & 4 \\
\hline & FSSH & 3.68 & 1.069 & 4 \\
\hline
\end{tabular}

A Mentor index (MI) is created using the twelve items on the scale to determine whether the four Faculties share similar views as regards to mentors in facilitating the learning process at practice settings. Descriptive statistics were carried out as illustrated in table 11(a). Students from the Faculty of Engineering tended to be more positive about the facilities offered by their mentors. A negative value of skewness for the four Faculties indicates a concentration to the right i.e. positive reaction towards the facilities offered by mentors. A negative value for kurtosis for FLM indicates that the distributions of MRI were flatter than normal for this faculty.

Table 11(a): MI statistics across the four Faculties

\begin{tabular}{lllll}
\hline Faculty & Mean & Variance & Skewness & Kurtosis \\
\hline FOE & 4.316 & 0.216 & -1.434 & 2.703 \\
FLM & 3.847 & 0.604 & -0.849 & -0.405 \\
FOS & 4.272 & 0.143 & -0.608 & 1.014 \\
FSSH & 4.027 & 0.212 & -0.491 & 0.348 \\
\hline
\end{tabular}

Kolmogorov-Smirnov and Shapiro-Wilk tests were performed to determine normality of the data and the test revealed that the data is not normal generating $\mathrm{p}$-values $<0.05$ for both cases as illustrated in table 11(b). 
Table 11(b): Tests of Normality

\begin{tabular}{lllllll}
\hline & \multicolumn{3}{l}{ Kolmogorov-Smirnova $^{\text {alm }}$} & \multicolumn{2}{l}{ Shapiro-Wilk } \\
& Statistic & df & Sig. & Statistic & Df & Sig. \\
\hline MRI & .126 & 83 & .003 & .934 & 83 & .000 \\
\hline
\end{tabular}

a. Lilliefors Significance Correction

Hypothesis was tested as to whether there is a difference in learning facilities offered by the mentors as viewed by students of the four Faculties. Kruskal Wallis which is a non-parametric test is used.

$\mathrm{H}_{0}$ : There is no difference in learning facilities offered by the mentors among the four Faculties.

$\mathrm{H}_{1}$ : There is a difference in learning facilities offered by the mentors among the four Faculties.

Table 12: Mean Rank by Faculty

\begin{tabular}{lll}
\hline & You are student from which Faculty & Mean Rank \\
\hline MRI & FOE & 53.42 \\
& FLM & 31.11 \\
FOS & 49.18 \\
FSSH & 35.68 \\
\hline
\end{tabular}

Table 13: Test Statistics ${ }^{a, b}$

\begin{tabular}{ll}
\hline Test & MRI \\
\hline Chi-Square & 11.839 \\
df & 3 \\
Asymp. Sig. & .008 \\
\hline
\end{tabular}

a. Kruskal Wallis Test

b. Grouping Variable: You are student from which Faculty

The results depicted in Table 13 shows that at 5\% significance level, there is consistency among the four Faculties as regards to the learning facilities $(\mathrm{p}>0.05)$ accepting the null hypothesis $\mathrm{H}_{0}$. The evidence suggests that students from FLM, FOS, FOE, FSSH shared similar views and agreed with the positive mentorship work in facilitating their WBL practice learning

\section{Conclusion \& Recommendations}

This study offers insights into the factors that foster the student-mentor relationship. The findings have shown that the above factors enhance the relationship, which helps in better engaging both students and mentors in the learning process. Trust, Empathy, Openness, Respect, Honesty, Care and Loyalty are the main ingredients that must be present for establishing a solid relationship. Deepening the relationship resulted in more commitment from both sides. To mentor and to be mentored are commitments of self and time. Neglecting any of these factors may lead to negative mentoring. It is clear that these factors help mentors in coaching and monitoring the training. Students on their side develop more confidence and are able to perform at their optimum level when these elements are present at the practice settings. 'Mentoring is seen to fulfill different needs at different times' (Waters et al., 2003: p. 524). As students show progress in the practice, the mentors' focus changed to meet new situations and increase the collaboration which results in better incentive for the students to work harder. This increases interactive capability where one sees self and the other as distinctive individuals with some relational connection which we can termed as human connection making both mentors and mentees receptive with the desire to meet again for a prolonged relationship. This study will prove much useful to mentors and prospective mentors in their effort to establish proper relationship with mentees where they can share their knowledge and ideas without 
conflicts. Mentees also are expected to benefit in that they become closer to the mentors and will be able to express themselves better which will greatly facilitate the transfer of knowledge.

\section{References}

Audet, J. (2009). Factors Leading to Satisfaction in a Mentoring Scheme for Novice Entrepreneurs. International Journal of Evidence Based Coaching and Mentoring, 7(1), 148-159.

Andrews, M. \& Wallis, M. (1999). Mentorship in nursing: A literature review. Journal of Advanced Nursing, 29(1), 201-207.

Byrne, M. \& Keefe, M. (2002). Building research competence in nursing through mentoring. Journal of Nursing Scholarship, 34(4), 391-396.

Clutterbuck, D. (1991). Everyone Needs a Mentor: Fostering talent at work (2nd Ed). London: Institute of Personnel and Development.

Cull, J. (2006). Mentoring young entrepreneurs: what leads to success? International Journal of Evidence Based Coaching and Mentoring, 4(2), 8-18.

Devojine, B. \& Harris, E. (2001). Developing the mentor/protégé relationship, Healthcare Executive, Chicago, July/August, p. 35.

Dingman, S. (2002). Mentoring connections: Learning relationships. Creative Nursing, 8(3), 9-11.

Donovan, J. (1990). The concept and role of the mentor. Nurse Education Today, 10(4), 294-298.

Eby, L., McManus, S., Simon, S. \& Russell, J. (2000). The protégé perspective regarding negative mentoring experiences: the development of a taxonomy. Journal of Vocational Behavior, 57, 1-21.

Hirst, P. (1971). What is Teaching? Journal of Curriculum Studies, 3, 5-18.

Kalinauckas P. \& King H. (1994). Coaching: realizing the potential. London: Chartered Institute of Personnel and Development.

Klasen, N. \& Clutterbuck, D. (2002). Implementing Mentoring Schemes: A Practical Guide to Successful Programs, Butterworth-Heinemann, Oxford.

Kram, K. \& Hall, D. (1989). Mentoring as an antidote to stress during corporate trauma. Human Resource Management, 28, 496-510.

May, K., Meleis, A. \& Winstead-Fry, P. (1982). Mentorship for scholarliness: Opportunities and dilemmas. Nursing Outlook, 30(1), 22-28.

McDowall-Long, K. (2004). Mentoring relationships: implications for practitioners and suggestions for future research. Human Resource Development International, 7(4), 519-34.

Miller, A. (2002). Mentoring Students and Young People: A handbook of Effective Practice London: Kogan Page.

Nermanick, R. (2013). Balance Empathy and Action. Leadership Effect. Available from: http://leadershipeffect.com/articles/the-mentors-way-rule-5-balance-empathy-and-action/. [10 December 2014]

Podsen, I. \& Denmark, V. (2000). Coaching and mentoring first year and student teachers. Larchmont, NY: Eye on Education.

Ragins, B., Cotton, J. \& Miller, J. (2000). Marginal mentoring: the effects of type of mentor, quality of relationship, and program design on work and career attitudes. Academy of Management Journal, 43(6), 1177-94.

Stewart, J. \& Knowles, A. (2003). Mentoring in undergraduate business management programs. Journal of European Industrial Training, 27(4), 147-159

Straus, S., Johnson, M., Marquez, C. \& Feldman, M. (2013). Characteristics of successful and failed mentoring relationships: A qualitative study across two academic health centers. Academic Medicine, 88(1), 82-89.

Sunderhaus, M. (2012). Mentor Attraction The Role of Protégé Personality, Mentors' Communication Style and Mentors' Work Experience.

Titchen, A. (2003). Critical companionship: Part 1. Nursing Standard, 18(9), 33-40.

Swanson, J. (2000). Zen leadership: Balancing energy for mind, body, and spirit harmony. Nursing Administration Quarterly, 24(2), 29-33.

Wanberg, C., Welsh, E. \& Kammeyer-Mueller, J. (2007). Protégé and mentor self-disclosure: levels and outcomes within formal mentoring dyads in a corporate context. Journal of Vocational Behavior, $70(2), 398-412$. 
Waters, D., Clarke, M., Ingall, A. \& Dean-Jones, M. (2003). Evaluation of a pilot mentoring program for nurse managers. Journal of Advanced Nursing, 42(5), 516-526.

Watson, N. (1999). Mentoring today-the students' views. An investigative case study of pre-registration nursing students' experiences and perceptions of mentoring in one theory/practice module of the Common Foundation Program on a Project 2000 course. Journal of Advanced Nursing, 29(1), 25462. 